\title{
Training research through EFL
}

\author{
Rimma M. Mardanshina ${ }^{1 \mathrm{a}}$,Marina G. Kudryavtseva ${ }^{1}$, Anisa A. Khusainova ${ }^{1}$ and Evgenia \\ E. Zhuravleva ${ }^{1}$ \\ ${ }^{1}$ Kazan (Volga Region) Federal University, 4 Butlerov Str., Kazan 420012, Russia
}

\begin{abstract}
In a globalized research market, developing students' research skills by means of a foreign language is of particular importance. Students' research work within the framework of the syllabus and extracurricular activities constitute the system of scientific work of students in a higher education institution. The potential of a foreign language in shaping the academic and research competence of students of Economics is revealed in the content and process aspects. Linguistics and economics as fields of scientific knowledge are reflected in the content aspect. Regarding the mode of training research, the emphasis is on reading strategies and activities aimed at fluent comprehension and handling professional and scientific information. Students' scientific conference survey proves the potential of EFL in research activities and sheds the light on the new ways to develop research competence.
\end{abstract}

\section{Introduction}

Nowadays, training research for undergraduate and graduate students is of particular importance. Enhancing the students' research is dictated, first, by the requirements of the federal state standards of higher education under which bachelors and masters of economics should be prepared, inter alia, to the analytical and research work in their professional activity; second, by the necessity to balance the academic and research work of students, for the latter to become a significant element in the intellectual development of students, nurturing their creativity, culture of thinking and their professional formation.

In recent years Russian scientists have considered the issues of students research work mainly in the context of teaching special courses, specifically, Fundamentals of Academic Work, Academic Writing, Discourse Analysis [11, 13 and 14], the use of information and communication technologies for the organization of students research [9 and 12]. Some aspects of building research competence of students by means of a foreign language have been studied in the framework of designing syllabus and technologies for Master's degree students [4 and 5], or for training managers in Russia [1].

The topic of our study is training research in the context of teaching English as a foreign language (EFL) for undergraduate and graduate students of economics at Kazan Federal

${ }^{\text {a }}$ Corresponding author: rimylja@mail.ru

(C) The Authors, published by EDP Sciences. This is an open access article distributed under the terms of the Creative Commons Attribution License 4.0 (http://creativecommons.org/licenses/by/4.0/). 
University (KFU), and the potential of EFL in the developing students' research skills is disclosed in terms of system approach.

\section{System Approach}

In this study, we presume that the academic and research work of students directly associated with the educational process and entered into the curriculum and syllabus, and extracurricular research activities constitute the system of students scientific work (SSW) in the conditions of multilevel education in Russia. System architecture allows settingits boundaries, model and structure; it also involves such system properties as hierarchy, integrity and synergy. The hierarchy positions the SSW as an element of multilevel education super-system and admits the existence of the system within the super-system. The latter involves organizing the academic and research work of students with the interim objectives to form the research skills of students at undergraduate, graduate and additional education levels (for instance, in the framework of complementary program "Translation for professional communication"). Integrity suggests the internal unity of the elements of the system, and it is determined by the overall goal of the SSW - building research competence. Synergistic capability of the system is greater than the sum of its constituent parts.

\subsection{Principles}

Furthermore, to design logically partitioned and integrated system of the SSW, planning principles should be taken into consideration. Russian researchers emphasizing the integrity of academic, upbringing and research processes, specify above all the principle of comprehensive scientific work of students, as it implies gradual assimilation, sequence and continuity of research methods and techniques in accordance with the level of instruction [2;7]. Our previous research has also demonstrated that "continuity (succession) as a pedagogical principle provides an organic relationship between and within various stages and levels of education; broadens and deepens knowledge acquired at the previous stages of education; converts individual ideas and concepts into a coherent system of students' knowledge and skills"[10].This fully implies to the formation of student's research competence under the conditions of multilevel education system in Russia. The principle of self-regulated research advanced by A. A. Khusainova [6] suggests expanding the range of active forms of independent research and formation of students' needs for lifelong learning.

We, in turn, have adapted Slastenin's principles of education in relation to training research by means of a foreign language in the form of content and procedural principles as they reflect primary didactic provisions: the body of information to be taught (what to teach) and the methods of teaching (how to teach). Taken together they can be manifested as the principle of optimality.

Hence, the main principles integrating the SSW comprise the principle of comprehensive scientific work, the principle of optimality, and the principle of selfregulated research.

\section{Curricular and extra-curricular research activities}

Further referring to the SSW within the context of teaching a foreign language in higher school of economics, we provide the necessary evidence of EFL potential in research competence formation revealing it in the content and process or procedural aspects. 


\subsection{Obligatory SSW}

Let us consider the obligatory component of the educational process, specifically, the academic and research work of students entered into the syllabus.

\subsubsection{Content aspect}

Any science, studied at the university as an academic discipline or group of disciplines, is implemented primarily in its educational content. Therefore, the content of students' research in higher educational institution of economics implemented through English and integrated into the overall content is based on the intersection of linguistics and economics. Hence these fields of scientific knowledge are reflected in the content aspect.

Linguistic part traditionally covers the phonetic, grammatical and lexical components. The latter, for instance, envisages the expansion of the vocabulary due to the lexical units constituting the basis of the scientific style register represented by the academic and science sub-style (terminological dictionaries, reference books, guidelines, authentic books on the basics of economic knowledge) and popular science sub-style (the BBC, Financial Times, Economist and Business Week articles). Since the scientific style of speech is characterized by the extensive use of terminology, the following fragment of the text can illustrate the degree to which special economic terms are used in EFL reading for the1st year students (the terms are in italics):

"The income tax in America is progressive: the more you earn, the more you pay. All taxpayers benefit from the system of tax allowances under which part of their income is taxfree..."

Here it should be noted that according to the research of the foreign language learning motivation offered by Elena M. Galishnikova [3], enlarging professional terminology and lexis is among the identified motives of KFU students. This indicator increases from $39 \%$ for undergraduates to $82 \%$ for students of "Translation for professional communication" program.

The economic sub-language of the scientific style is represented by the thematic epistemic of the basics of macro- and microeconomics (Great Britain Economy, US Economy, Credits, Taxes, Entrepreneurship, Types of Businesses etc.).Addressing the subject content of education from the standpoint of epistemology allows positioning the training episteme as balanced, logically completed part of the content of the discipline with an appropriate form of control of knowledge, skills and competences formed as a result of mastering this or that episteme and expressed in the creation of student's final educational product(abstracts, presentations). The latter may be categorized as reproductive abstracts or summaries, if they cover main provisions of an original source, and productive summary reviews embracing several original sources; theyfall into General English abstracts and professionally oriented ones. To exemplify, the extension of the episteme Great Britain is made in the following areas:

Great Britain economy in general;

- the development of Great Britain economy over the past decades;

- key sectors of the economy;

- monetary policy etc.

Thus, linguistic and thematic components of EFL constitute the subject content of education, where linguistics and economics as spheres of scientific knowledge are reflected. 


\subsubsection{Procedural aspect}

Procedural aspect is represented by the skills to use the acquired knowledge for the purpose of oral and written communication. EFL communicative approach requires confident use of language in speech activities (speaking, listening, reading and writing), all of which directly or indirectly relate to scientific communication. Moreover, the practical proficiency of English for specific purposes involves, above all, the ability to work independently with authentic sources in order to obtain professional information. Positioning text activities as the starting point of any scientific research, we focus on mastery of effective reading techniques enabling students to handle large amounts of information. The recognized methods of effective reading, which make up the techniques of quick search for information and adapting multiple sources, are:

-skim reading to identify the main idea of a paragraph, page, chapter, or general idea of the text;

-scanning to search for specifically required information;

-surveying the text to review the output data (title, sub-titles, details about the author, table of contents etc.);

-using the title to formulate the questions that you expect the text to answer.

Mastery of quick and effective reading techniques allows processing large amounts of information and serves as the basis for building students' research competence. Some elements of these techniques are used for undergraduate students, but the whole range of them is actively put into practice for graduate students of economics at the Institute of Management, Economics and Finance, KFU.

Thus, it can be asserted that the content of the research activities stipulated by EFL program is interdisciplinary as it combines two spheres of scientific knowledge - linguistics and economics. The procedural aspect is represented by the skills to use the acquired knowledge for the purpose of oral and written communication where reading comprehension as the basis of scientific communication takes the lead.

\subsection{Non-obligatory SSW}

Presuming that the academic and research work of students directly and indirectly associated with the educational process constitute the system of SSW, nowwe turn to the extracurricular research activities of students. The implementation of the competence approach in the system of higher education presupposes the extensive use of active methods of learning; these include scientific and practical conferences, group discussions, subject Olympiads etc. The annual event of the Department of foreign languages in the field of economics, business and finance is the students' scientific conferences and round table discussions where English is used as the medium of scientific communication.

\subsubsection{Student conference survey}

As part of the regular event, the participants of Students' Scientific Conference 2014 were surveyed to identify the role of a foreign language in enhancing students' research work. Survey items included:

-composition of the participants;

-choice of the research topic

-the use of English and Russian sources and their number;

-intention to continue the research on the topic chosen;

-motives of participation in the conference. 
-The following survey results may be noted as positive ones:

- the main motive of participation in the conference of the students of all levels of education (those undertaking bachelor's and master's degreeprograms, and additional education program) is their interest to the topic chosen and their attitude to the foreign language they study $-80 \%$ of respondents respectively;

- $70 \%$ of the participants were senior undergraduates, although English is taught for the first- and second-year students doing Bachelor's degree;

-English and Russian sources were used in almost equal propotion, and the usage of Russian materials means that translation as one of the main types of written communication was implemented;

-more than $50 \%$ of the participants showed their intention to continue their research on the topic chosen.

The number of sources adapted varied between 2 and 3, and it is not enough especially for graduate students. With regard to the composition of the rest of the participants, it was distributed as follows: $20 \%$ were first-year students, and only $10 \%$ were students undertaking Master's degree programsfor whom research work is, in fact, the main focus of study.

\section{Conclusion}

In general, the potential of EFL in building the students research competence disclosed in the framework of content and procedural components has been confirmed by the survey results. However, it also shed the light on the necessity of finding new ways to intensify the process of training research especially for Master's degree students

\section{References}

1. Baklashova, T.A., Manager's professional training in Russia: Syllabus and technologies. Procedia - Social and Behavioral Sciences, 152, 1057-1067, (2014)

2. Fedosova, I. V., School for young researchers as a form of improving the quality of students research work.Modern problems of science and education, 6.http://www.science-education.ru/19-630, (2006)

3. Galishnikova, E.M., Language learning motivation: a look at the additional program. Procedia - Social and Behavioral Sciences, 152, 1137-1142, (2014)

4. Gorelova, Y.N., Zalyaeva, E.O., \& Sungatullina, D.D., Building Research Competence of Graduate Students by Means of Teaching English for Academic Purposes.Mediterranean Journal of Social Sciences, 6 No 1 S3, 352-356, (2015)

5. Ismagilova, L.R., \&Polyakova, O.V., The Problem of the Syllabus Design within the Competence Approach based on the Course "English for Master Degree Students in Economics (Advanced Level)". Procedia - Social and Behavioral Sciences, 152, 10951100, (2014)

6. Khusainova, A. A., Formation of socio-cultural self-determination of technical college students by means of a foreign language: dissertation ... Candidate of Pedagogical Science. Joshkar-Ola, (2007)

7. Khusainova, A.A., \&Rahmatullina, A.R. English language training volunteer program as a new reality for Russia and its social benefits.Procedia - Social and Behavioral Sciences, 152, 1101-1107, (2014)

8. Kouprianov, A., Academic writing and academic form of life trying to adapt the course of academic writing in an unfriendly institutional milieuHigher Education in Russia, $10,30-38,(2011)$ 
9. Kudryavtseva, M.G., Possibilities of distance learning as a means of foreign language learning motivation among students of economics.Procedia - Social and Behavioral Sciences, 152, 1214-1218, (2014)

10. Mardanshina, R., \&Zhuravleva, E., Model of complementary linguistic education for economists.Procedia - Social and Behavioral Sciences, 152, 1091-1094, (2014)

11. Orlova, G., Practical analytics: teaching discourse analysis through the university curriculum. Higher Education in Russia, 7, 127-133, (2011)

12. Gospodarik, Yu., The use of internet technologies in the organization of nirs. Higher Education in Russia, 2, 115-121 (2012)

13. Robotova, A., Is it necessary to teach the academic work and academic writing? Higher Education in Russia, 10, 47-55 (2011)

14. Stepanov, B., Communication dimension of science in teaching the academic writing.Higher Education in Russia, 7, 123-127 (2011) 